\title{
Developmental Immunotoxicity of Aluminium Containing Food Additive: an Experimental Study
}

\author{
Ghada A. Omran, Michael N. Agban'1, and Safaa M. George²
}

${ }^{1}$ Department of Forensic Medicine and Clinical Toxicology
${ }^{2}$ Department of Microbiology and Immunology

Faculty of Medicine, Assiut University, Assiut, Egypt.

Corresponding author: Dr. Ghada Ali Omran

Email: ghada_ali@hotmail.com

Phone: +20882411895

\begin{abstract}
Aluminium (Al) compounds occur naturally in the environment and are used for different purposes such as water treatment, food additives and pharmaceuticals. Its potential toxicity on human has been documented but still the immunotoxic behaviour is debated. The current study aimed at exploring the effect of developmental exposure to $\mathrm{Al}$ on both cell mediated and humoral immunity on rats' offspring. Twenty pregnant albino rats in four groups (5 dams/group) were orally exposed to aluminium ammonium sulphate in 50,100 and $200 \mathrm{mg} / \mathrm{kg} /$ day in addition to a control group for five days a week during conception, pregnancy, lactation till weaning of pubs. Then forty female offspring of the treated mothers in four groups (10 rats each) were maintained with the same Al doses whenever they can be directly dosed until reached 8 weeks old(near adults) so all critical windows of immune development were examined. Total body weights, spleen and thymus relative weights along with total and differential leukocytic counts were evaluated for juvenile rats. Three immunoglobulins (IgG, IgM, and IgE) in addition to two cytokines, interferon- $\delta$ (IFN- $\delta$ ) and tumor necrosis factor- $\alpha$ (TNF- $\alpha$ ) were measured as indicators of humoral and cell mediated immunity. Results indicated reduced body weights by dose increment and this was concomitant to increase in relative thymic and splenic weights. The concentration of TNF- $\alpha$ and IFN- $\delta$ were elevated especially with highest Al dose but other immunoglobulins, IgG and IgM showed insignificant change versus controls while IgE displayed decline in its level most observed with maximum dose group compared to controls. Total white blood cell count did not change significantly from controls but relative lymphocytosis was observed. The present results proved the developmental immunotoxic effect of the aluminium compound investigated, mainly of cell mediated type. Further research is needed to examine specific critical stages of immune development in response to $\mathrm{Al}$ exposure as well as differential gender susceptibility.
\end{abstract}

Keywords Aluminium, developmental, immunotoxicity, experimental

\section{Introduction}

A luminium (Al) occurs naturally in the environment and is the third most abundant metallic element in earth's crust (Domingo, 1995). A variety of Al compounds are produced and used for different purposes such as water purification, food additives, cooking ware and pharmaceuticals. Notably, the non-prescription drugs such as some antacids, buffered aspirins, antidiarrheal products, haemorrhoidal medications and many vaccines contain considerable amounts of Al as an adjuvant. The major route of $\mathrm{Al}$ exposure for general population is through food and drinking water to a minor extent. Many unprocessed foods contain higher concentration of Al e.g. breads, cakes, biscuits, some vegetables, dairy products and even infants formulae. In addition, Al migration from food contact materials (cooking utensils and aluminium foils) slightly contributes to the total dietary intake that is especially increased in the presence of acids and salts like tomato-containing foods and vinegar in pickles for examples (Aguilar et al., 2007). The bioavailability of oral aluminium is enhanced by the solubility of the compound used and 
the presence of dietary legends in the intestine that either increase its absorption e.g. citrate, lactate and organic acids or decrease it e.g. phosphates and silicon. After Al absorption it distributes to all body tissues and accumulates in particular in bones and brain. It also can reach the placenta and foetus and it persists for long times in various organs before it is excreted in urine (Alfrey, 1986 (a); Gupta et al., 1986; Johuanneau et al., 1994).

The European parliament and Council has allowed a number of aluminium-containing food additives to be used in some foodstuffs other than sweeteners and colorants. Particularly aluminium sulphates (E520-523) are permitted in egg white and candied fruits and vegetables. Meanwhile, aluminium ammonium sulphate (alum) is used as an effective food colour fixative, firming agent and a preservative in many foods in addition to water purification. Additionally, acidic sodium aluminium phosphate (E541) is used in bakery and sponge wares while aluminium silicates (E553-559) are employed in a wide range of food categories (Aguilar et al., 2007). Many of those additives have not got full toxicological profiles. However, several previous studies have reached the same conclusion that $\mathrm{Al}$ is potentially toxic to human. The patients on dialysis who are chronically exposed to Al via parentral route have shown signs of neurotoxicity (Alfrey, 1986 (b)). There are also many studies that justified Al implication in neurodegenerative diseases in human e.g. Alzheimer's disease (Exley, 2001; Exley, 2005). Male reproductive adverse effects in the form of testicular toxicity, reduced sperm quality and reduced fertility, have been observed in dogs and rodents as well (Llobet et al., 1995; Chih-Hung et al., 2005). In addition, Al has induced embryotoxic and teratogenic liability (Paternain et al., 1988) remarkably on the developing nervous system that reflects as neurobehavioral deficits in rodents (Alleva et al., 1998; Roig et al., 2006). Farina et al,(2002) have reported anaemia signs as a result of chronic Al sulphate administration as well.

Still many aspects of Al toxicity are unrevealed. Immunotoxicity is one of deficient areas as a result to Al exposure especially for the developing offspring. The developing immune system is a remarkably sensitive toxicologic target for environmental chemicals and drugs (Dietert and Piepenbrink, 2006). In fact, the perinatal period is full of dynamic immune changes, many of which do not occur in adults. Moreover, early life exposure to toxicants constitutes the greatest environmental risk for the immune system that is expected to greatly affect subsequent adult health e.g. risk of atopy, autoimmune disease and later life immune balance that contributes to cancer development. Thus, children are specifically at risk based on increased consumption of many readymade Al-containing foods nowadays (Luebke et al., 2006). Noteworthy, some related compounds to Al (heavy metals) such as arsenic and lead have demonstrated immunotoxic effects following developmental exposure in rodents (Sikorski et al., 1989; Bunn et al., 2001; Patterson et al., 2004). Extrapolation of immunotoxic risks associated with many environmental toxins has been justified for application to human (Selgrade, 2007).

The Immune System (IS) is the body's major defence against invading microorganisms such as viruses, bacteria, protozoa, fungi and parasites. Various stimuli, such as environmental toxicants, affect immune-competence, and the host's ability to fight off infectious agents, which can ultimately result in disease or mortality. Stimulation of the IS by the presence of foreign substances (i.e. antigens) in a host organism results in a variety of orchestrated responses. There are two components of the IS: innate and adaptive immunity. The innate immune response is an immediate, generalized, rapid response such as naturally existing anatomical barrier like skin, physiological barriers like fever or chemical barriers like complement activation. If needed, the innate immune component will activate adaptive immune cells as a second-line of defence. The cells of adaptive immunity, called lymphocytes, are able to mount precise attacks against foreign invaders. A humoral immune response is mediated by B lymphocytes (Bcells), which are stimulated to produce antibodies in the presence of extracellular invaders. Intracellular invaders stimulate $\mathrm{T}$ lymphocytes (T-cells), either cytotoxic-T cells (CTLs) or helper T-cells. While cytotoxic T-cells can attack an invader directly, helper T-cells help B-cells attack. Ultimately, once the invader is eliminated some B- and T-cells remember the intruder in order to mount a faster response upon subsequent encounters. Lymphocytes secrete small molecules called cytokines. Cytokines, similar to hormones except that they usually exert their effects much more locally, are the messengers that play a pivotal role in the immune response to foreign invaders. One way cytokines control immune responses is by influencing and changing the balance of $\mathrm{T}$ helper 1 (Th1) and $\mathrm{T}$ helper 2(Th2) cells, cell trafficking, and growth, as well as activation of the lymphocyte subpopulations (Oberholzer et al ., 2000).

Th1 responses are usually implicated in the control of viral infections and other intracellular pathogens. The Th2 response, which promotes antibody production, is most often associated with larger microorganisms, such as free-living bacteria and helminthic parasites. This response is also important in the generation of an allergic reaction. When there is an overabundance of Th1 cells (relative to Th2 cells), cellmediated immunity is induced, including the activation of CTLs and the delayed-type hypersensitivity reaction. When Th2 cells predominate, the humoral arm (antibody production) of the immune response becomes engaged (Romagnani et al, 1998). Moreover, through synergistic and antagonistic effects on one another, cytokines act to offset immune responses by down-regulation, a mechanism, which is a key to the cytokine network (Pabello and Lawrence, 2006). The effects of $\mathrm{Al}$ on immune function are still controversy, some researchers showed that Al suppressed immune function (Tzanno-Martins et al., 1996; Ward et al., 2006)but other studies observed the opposite results (Glynn et al, 1999; Jordan et al., 2004). Recently, Zhu et al, (2013) reviewed the association of Al with 
autoimmunity, hypersensitivity, and erythrocyte immune function via interaction with complement system.

The present study aimed at investigating the immune hazards associated with aluminium ammonium sulphate (E523) administration as a member of Al sulphate group of food additives (E520523) in developing rat offspring. Determining the pattern of immunotoxic effect either humoral or cell mediated, in offspring exposed to $\mathrm{Al}$ in utero and during the postnatal period was another main objective.

\section{Materials and methods}

\section{Animal groups and experimental design}

The experimental procedures were carried out after ethical approval according to the Guidelines of the National Institutes of Health for Animal Care followed within the Faculty of Medicine, Assiut University, according to referenced authority (Institute of Laboratory Animal Resources, 1996). A total of 20 healthy adult female albino rats of 4-5 months old (with average weight $200 \pm 50 \mathrm{~g}$ ) were purchased from Faculty of Medicine's Animal House. The animals were maintained under temperature $22-25{ }^{\circ} \mathrm{C}$, a $12 \mathrm{~h}$ light/dark cycle, adlibitum availability of pellet food and water. The experimental groups were randomly divided into four groups of adult female rats that were housed with males ( 5 dams per each group). Three groups of those had received different doses (50, 100, $200 \mathrm{mg} / \mathrm{kg} / \mathrm{day}$ ) of aluminium ammonium sulphate compound (A018112, Qualikem, India) that was dissolved in distilled water. In addition, a control group had received only distilled water. The Al dose regimen was chosen by guidance of Gomez and coworkers (1991) and was given the form of a single daily oral gavage dose for 5 days/week. That treatment was given to dams during breeding, conception, pregnancy and lactation till weaning of pups or whenever they can be directly dosed so all critical windows of immune development were examined in the offspring only. At least 10 female pubs per group were allowed to continue administration of different aluminium doses till 8 weeks old (the immune parameters reach near adult status) (Holsapple et al., 2005).At this time point animals were anesthetized with ether and bled by cardiac puncture. Whole blood was drawn into heparin containing tubes for total and differential blood counts and immunologic parameters testing. Brain and livers were also quickly removed and kept frozen till analysed for Al level (Farina et al., 2002). Offspring weights were recorded weekly until sacrificed.

\section{Aluminium level determination}

Aluminium levels per each group were determined using liver and brains as target tissues. Frozen tissues were allowed to equilibrate to room temperature. A fraction of each organ (approximately 0.1-0.3gm) was digested with $7 \mathrm{ml} 69 \% \mathrm{HNO} 3$ in a digestion microwave (Multiwave 3000, Anton Paar, Austria) under the manufacturer recommended operating conditions to digest tissue samples. Subsequently, samples were diluted with deionised water in 1: 25 ratio, and then filtered prior to analyses for Al. An Inductively Coupled Plasma Atomic Emission Spectrometer, iCAP 6200 ICP Spectrometer (Thermo Scientific, USA) were used for Al analysis according to Gomez, et al, (1999) in the Central Laboratory, Faculty of Agriculture, Assiut University.

\section{Haematological parameters determination}

Total red blood cells, haemoglobin, total and differential white blood cell counts were determined for each group using automated haematology analyser (MICROX60-ABX Diagnostics, Montpellier, France).

\section{Immunological parameters assays}

The collected blood samples were centrifuged for plasma collection and immune function testing after complete blood pictures were analysed. Assessment of structural integrity of the immune system through measuring spleen and thymus weights to total body weight (organ weight index) were determined after trimming of fat. Innate immunity was assessed by estimating total and differential blood counts as mentioned above. The humoral immune response was evaluated by measuring total immunoglobulins or antibodies (IgE, $\operatorname{IgM}$ and $\operatorname{IgG}$ ). Cytokines such as tumour necrosis factor (TNF- $\alpha$ ) and interferon- $\gamma$ (IFN$\gamma$ ) were determined for cellular immunity assessment. All antibodies and cytokines concentrations were measured using Enzyme Linked Immunosorbent Assay (ELISA) technique as per kits manufacturer's recommendations (KOMBIOTECH, Korea).

\section{Statistical analysis}

The resulting data of various groups were subjected to statistical analyses. Descriptive data such as means and \pm SE (standard error of the mean) were calculated. Comparisons of $\mathrm{Al}$ treatment groups to controls and to each other were undertaken to figure out any significant differences. One-way analysis of variance (ANOVA) was used (IBM SPSS v.19). A multiplecomparison test (post hoc) was employed if significance was indicated by ANOVA with a probability level $<0.05$.

\section{Results}

\section{1) Offspring general and relative lymph organs weights}

There was a significant dose dependent decrease in the mean total body weights of female offspring versus controls as aluminium ammonium sulphate (AAS) dose increases (Figure 1). This was concomitant with increase in relative thymic weights especially in 100 and $200 \mathrm{mg}$ Al- treated groups when compared with controls and $50 \mathrm{mg}$ group, with the highest effect being in $200 \mathrm{mg}$ group (Figure2).In comparing splenic weights, $50 \mathrm{mg} \mathrm{Al}$ did not differ from controls significantly but weights have increased with $100 \mathrm{mg}$ group and decreased again but insignificantly in the highest dose group (200 mg/kg AAs). The latter 2 groups were highly differentiated from controls and 50 mg group (Figure 3). 


\section{2) Organs' aluminium level}

Figure (4) presents liver and brain Al concentrations in different treated groups. Hepatic concentration of Al did not vary significantly between treated groups except in highest dose group in contrast to controls.On the other hand, brain levels has increased gradually by increment in doses till reached maximum level in 200 $\mathrm{mg} / \mathrm{kggroup}$. This is reflected through significant differences between controls and $50 \mathrm{mg}$ group in one side and 100, $200 \mathrm{mg}$ groups on the other side. Additionally, there was a significant high Al level of brains when compared with livers in offspring that received the 2 maximum dosages $(P=0.012$ in 100 $\mathrm{mg} / \mathrm{kg}$ group and $p<0.001$ in $200 \mathrm{mg} / \mathrm{kg}$ ).

\section{3) Hematologic parameters}

Table (1) shows the hematologic parameters in juvenile female offspring (8 weeks old) that received aluminium ammonium sulphate prenatal and postnatal. A significant decrease of haemoglobin level was observed only in high Al doses $(200 \mathrm{mg} / \mathrm{kg})$ in comparison to controls. Erythrocytes and platelet counts did not differ among treated groups but the total leukocytic counts displayed significant decrease in each group when compared to control group.
Differential white blood cell counts displayed significant lymphocytosis and neutropenia when compared against controls. Moreover, monocytes and eosinophils decreased significantly in Al treated groups in relation to controls.

\section{4) Immunologic parameters}

Cell mediated and humoral immune markers of female offspring in different Al doses treated groups were measured and presented in table (2). Interferon- $\gamma$ (T helper type-1 immunity) showed a dual pattern, decreased in $50 \mathrm{mg}$ and $100 \mathrm{mg}$ treatment groups which were significant in the latter group, then increased significantly in juvenile rats received 200 $\mathrm{mg} / \mathrm{kg}$ compared to controls. Tumor necrosis factor- $\alpha$ showed minimal gradual increase in its level then elevated remarkably only in the highest $\mathrm{Al}$ dose group versus controls.

Regarding immunoglobulins as markers for humoral immunity and B lymphocyte function, $\operatorname{IgG}$ and IgM displayed no significant change among groups or in relation to controls. Meanwhile, IgE showed minimal decline as $\mathrm{Al}$ doses increase but only the 50 and $200 \mathrm{mg}$ groups' differences were significant compared to controls.

Table (1): Statistical analysis (ANOVA) of aluminium effects on hematologic parameters in different AAS treatment groups ( $n=10$ offspring per group). Each value represents the mean + SE.

\begin{tabular}{|c|c|c|c|c|}
\hline Hematologic parameter & Control (a) & 50 mg AAS(b) & $100 \mathrm{mg}$ AAS (c) & $200 \mathrm{mg} \mathrm{AAS} \mathrm{(d)}$ \\
\hline $\mathrm{Hb}(\mathrm{g} / \mathrm{dL})$ & $8.14+0.24$ & $7.78+0.32$ & $8.225+0.37^{\mathrm{d}^{* * *}}$ & $6.9 \pm 0.39^{\mathrm{a}^{* * *}}$ \\
\hline $\operatorname{RBCs}\left(10^{3}\right.$ cell $\left./ \mathrm{mm}^{3}\right)$ & $5.51+0.42$ & $4.683+0.39$ & $5.448+0.38$ & $5.83+0.49$ \\
\hline WBCs $\left(10^{3}\right.$ cell $\left./ \mathrm{mm}^{3}\right)$ & $7.66+0.69$ & $4.99+0.59^{\mathrm{a}^{* *}}$ & $5.19+0.65^{\mathrm{a}^{*}}$ & $6.73+0.75^{\mathrm{a}^{* *}}$ \\
\hline Neutrophils (\%) & $21.33+4.44$ & $8+1.16^{\mathrm{a}^{* * *}}$ & $13.75+1.86^{\mathrm{a}^{*}}$ & $17.67 \pm 2.37^{\mathrm{a}^{* *}}$ \\
\hline Lymphocytes (\%) & $72.67+4.71$ & $87.33+1.58^{\mathrm{a}^{* * *}}$ & $82.33+1.89^{\mathrm{a}^{*}}$ & $86.83+2.45^{\mathrm{a}^{* * *}}$ \\
\hline Monocytes (\%) & $5.33+1.12$ & $5.5+1.12$ & $2.67+0.42^{\mathrm{a}^{*}, \mathrm{~b}^{*}}$ & $2.8+0.327^{\mathrm{a}^{*}, \mathrm{~b}^{* *}}$ \\
\hline Eosinophil (\%) & $7+0.58$ & $2^{\mathrm{a}^{* * *}}$ & $3.8+1.63^{\mathrm{a}^{* *}}$ & $2^{\mathrm{a}^{* * * *}}$ \\
\hline Platelets $\left(10^{3}\right.$ cell $\left./ \mathrm{mm}^{3}\right)$ & $540+56.68$ & $618.33+48.25$ & $548.33+25.28$ & $463.33+44.7^{\mathrm{b}^{*}}$ \\
\hline
\end{tabular}

Hb; haemoglobin, RBCs; red blood cells, WBCs; white blood cells, AAS; aluminium ammonium sulphate.

Letters with asterisks represent significant differences between treatment groups (b, $c$ or $d)$ or controls (a). $* P<0.05, * * P<0.01, * * * P<0.001$.

Table (2): Statistical analysis (ANOVA) of aluminium effects on cytokines and immunoglobulins in different AAS treatment groups ( $n=10$ offspring per group). Each value represents the mean $+\mathrm{SE}$.

\begin{tabular}{|c|c|c|c|c|}
\hline Immunologic parameter & Control (a) & 50 mg AAS (b) & 100 mg AAS (c) & 200 mg AAS (d) \\
\hline INF- $\gamma(p g / m l)$ & $3054.17+709.54$ & $2555.67+528.81$ & $2766.42+168.01^{\mathrm{a}^{*}}$ & $3777.17+387.77^{\mathrm{a}^{* *}}$ \\
\hline $\mathrm{TNF}-\alpha(p g / \mathrm{ml})$ & $277.83+6.44$ & $301.92+9.80$ & $347.71+54.17$ & $1115.17+426^{\mathrm{a}^{* * *}, \mathrm{~b}^{* *}, \mathrm{c}^{* *}}$ \\
\hline $\operatorname{IgG}(n g / \mathrm{ml})$ & $62+5.64$ & $67.33+6.22$ & $71.33+7.22$ & $62.17+5.25$ \\
\hline $\operatorname{IgE}(n g / \mathrm{ml})$ & $5.71+0.65$ & $4.11+0.22^{\mathrm{a}^{*}}$ & $4.53+0.26$ & $4+0.26^{\mathrm{a}^{*}}$ \\
\hline $\operatorname{IgM}(n g / m l)$ & $34.17+2.97$ & $19.67+0.54$ & $29.08+3.059$ & $27.17+3.4$ \\
\hline
\end{tabular}

AAS; aluminium ammonium sulphate.

Letters with asterisks represent significant differences between treatment groups (b, $c$ or $d)$ or controls (a).

$* P<0.05, * * P<0.01, * * * P<0.001$. 


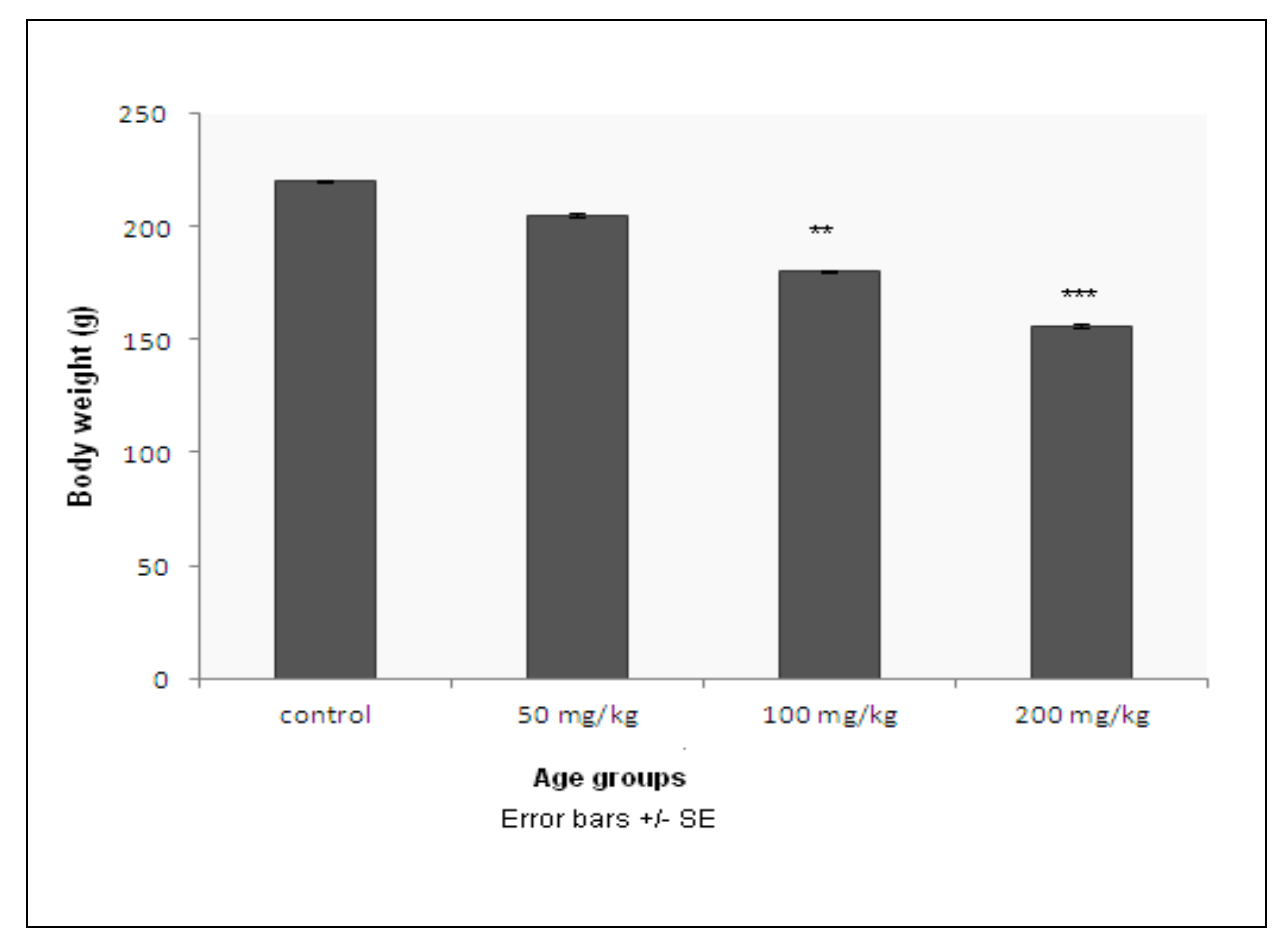

Figure (1): Effect of different oral doses of aluminium ammonium sulphate exposure on body weight of rat's offspring (10 female rats for each group). Bars present means $+/$ - SE. $* * P<0.01, * * * P<0.001$ versus controls.

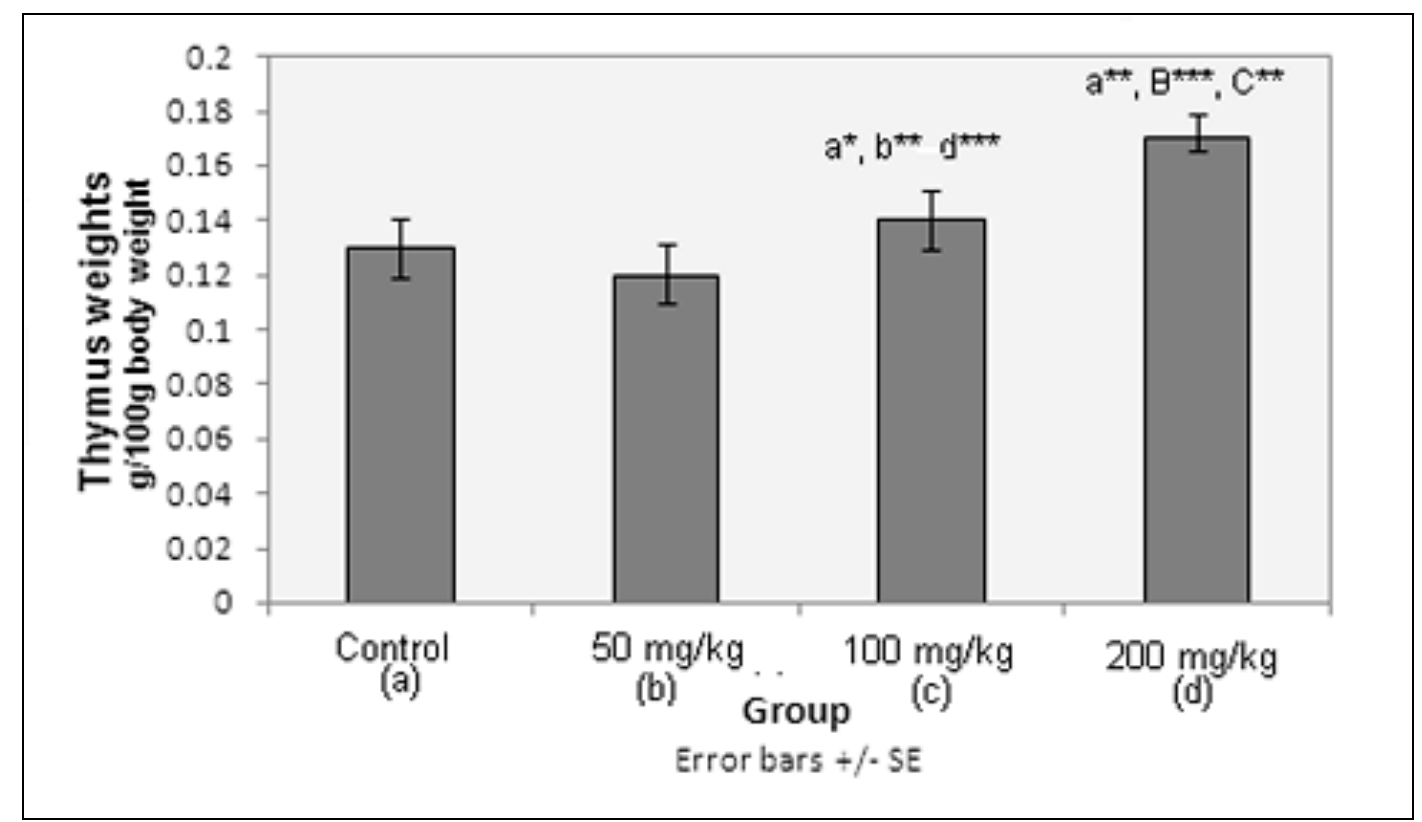

Figure (2): Relative thymus weights (g/100g body weight) in female rat offspring (8 weeks old) exposed to different AAS doses. The results are expressed as means + SE $(n=10$ per treatment group). Letters with asterisks represent significant difference with corresponding groups $(b, c$, or $d)$ or controls $(a) . * P<0.05, * * P<0.01$, $* * * P<0.001$. 


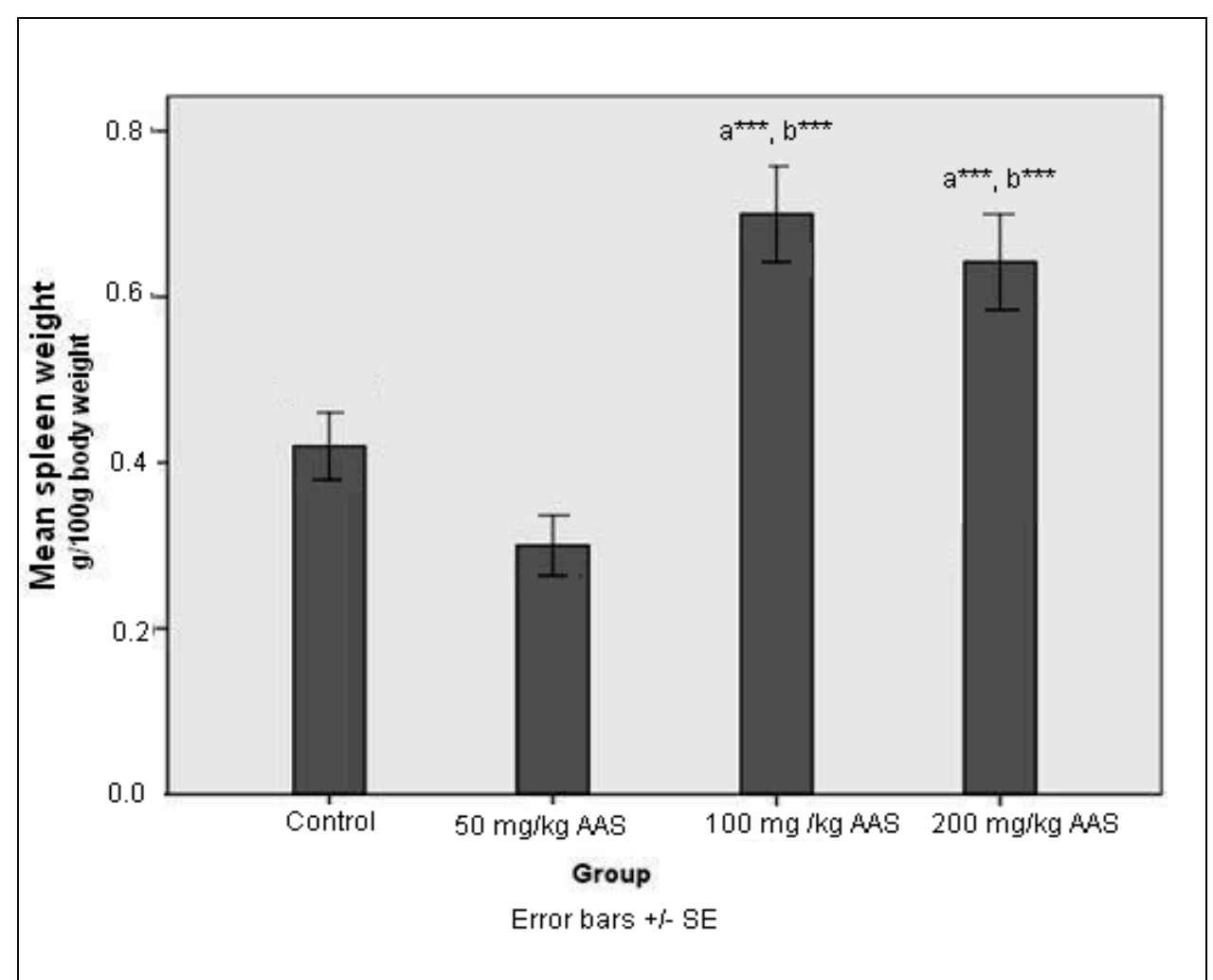

Figure (3): Relative spleen weights (g/100g body weight) in female rat offspring (8 weeks old) exposed to different AAS doses. The results are expressed as means $\pm \mathrm{SE}(n=10$ per treatment group). Letters with asterisks represent significant difference with corresponding groups $(b, c$, or $d)$ or controls $(a) . * * P<0.001$.

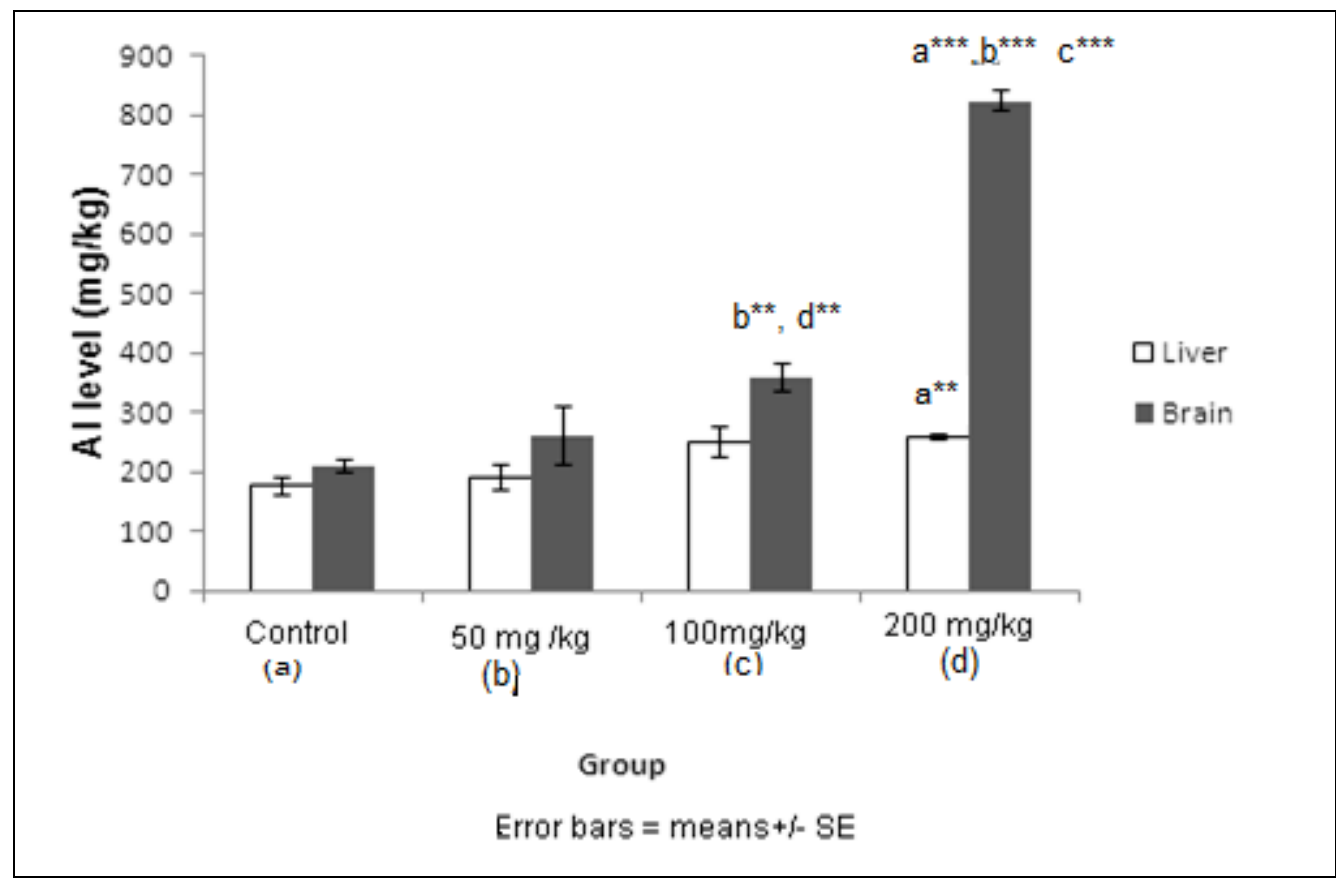

Figure (4): Liver and brain aluminium levels in different AAS dosage groups $(n=10$ per each group). Each value represents the mean $\pm \mathrm{SE}$ in $\mathrm{mg} / \mathrm{kg}$. Letters with asterisks represent significant difference with corresponding groups (b, c or d) or controls (a). $* * P<0.01, * * * P<0.001$.

\section{Discussion}

Aluminium (Al) is among the most common metals in earth's crust and it has no known biological function. Exposure to aluminium is unavoidable during the entire life-span. It enters the human body via food as a major source, water, air and drugs. Human consumes an average of $7600 \mu \mathrm{g}$ /day from food and drinking water (Yokel and McNamara, 2001). However, other additional Al sources such as widely used food additives or cosmetics and drugs increase the level of exposure in some population subgroups. Pregnant women are potentially exposed to Al through diet and some medications. Children are also at high risk owing 
to increased consumption of many ready-made foods that contain a variety of aluminium-containing food additives. They are mostly added to consumer foods as thickeners, acidity modifiers or anti-caking agents (Aguilar et al, 2007). Furthermore, $\mathrm{Al}$ is known to be a potent stimulant of the immune system, which is the main reason to its use as a vaccine adjuvant (Tomiljenovic and Shaw.2011; Batista-Duharte, 2011) but it also has the potential of immunotoxicity to human and animals (Rengel, 2004). However, its effects on the immune function are controversy, some researchers showed that Al suppressed immunity (Tzanno-Martins et al, 1996; Ward et al, 2006) but other reported the opposite (Glynn et al, 1999; Jordan et al, 2004).

The results of the present study showed decrease in total body weight observed in the offspring with increasing $\mathrm{Al}$ doses which is documented as a general sign of toxicity in accordance of other investigators work (Zhu et al., 2012). The relative increase in thymic and splenic weights (primary and secondary lymphoid organs respectively), were observed in a dose dependant fashion. This may be elucidated via relative lymphocytosis and aluminium accumulation in these organs as also supported through other organs increment in Al concentration specially brains (Gupta et al., 1986). Those finding were observed with late gestational exposure to other metals like lead in female offspring (Bunn et al, 2001). Differential brain elevation of Al level may be related to the neurobehavioral changes and development of Alzheimer disease as described earlier (Exley, 2001; Exley, 2005). Recently, a reciprocal interaction between nervous and immune system via hypothalamic- pituitary -adrenal axis and the autonomic nervous system have gained much attention and led to the development of a field of neuroimmunotoxicology as reviewed by Pabello and Lawrence (2006).

Regarding the total leukocytic count, it did not differ significantly among treatment groups with relative lymphocytosis and decrease monocytes when compared to controls. This is partially in agreement with Bunn et al, (2001) who found relative monocytosis in addition to normal white blood cell counts as well in rat offspring exposed to lead early and late in gestation. Furthermore, there was a decline in haemoglobin concentration associated with the high oral dose $(200 \mathrm{mg} / \mathrm{kg})$ during perinatal exposure to aluminium ammonium sulphate in rats' offspring. However, red blood cell counts were not affected. In agreement of several previous studies that pointed to aluminium (Al) as an exogenous factor responsible for developed anaemia signs both in patients on haemodialysis (Parkinson et al., 1981) and in experimental animals (Zaman et al., 1993; Fulton and Jeffery, 1994). This was explained through various mechanisms in previous studies. For example, Farina and associates (2005) examined the hematologic effects of the long-term oral exposure to low doses of Al sulphate $(55 \mathrm{mg} / \mathrm{kg})$ in female rats. They concluded that alterations on erythrocyte parameters and signs of anaemia are enhanced through intravascular haemolysis caused by increased oxidative stress and lipid peroxidation in the circulating erythrocytes with consequent decrease in erythrocytic membrane fluidity in agreement with other former study as well (Vittori et al., 1999). Changes caused by aluminium administration on the iron metabolism were reported as a leading cause for development of anaemia (Nasiadek et al, 2001; Farina et al., 2002; Farina et al, 2005). Moreover, the effect of high Al concentrations on the activity of $\delta$-aminolevulinic acid dehydratase ( $\delta$-ALAD) was another proposed mechanism for development of anaemia as it catalyses the second step in the heme biosynthetic pathway (Jaffe et al., 1995). In vivo studies with rodents have yielded conflicting results regarding this. Zamanet al. (1993) reported that Al inhibits $\delta$-ALA-D activity and that this inhibitory phenomenon is associated with signs of anaemia while Farina et al., (2005) figured out a stimulatory effect of chronic aluminium exposure on bone marrow $\delta$-ALAD.

The development of the immune system in the embryo involves rapid differentiation of progenitor cells. Around day 9 of gestation in rats, migration of stem cells to the fatal liver and spleen occur with colonization of bone marrow and thymus occurring by day 13 until birth. Thymocytes express CD4 and CD8 by day 14 and monocytes are detected in circulation at day 12 or later (Holladay and Smialowicz, 2000). This time of gestational development of these cells corresponds primarily to the first half of gestation in humans (Bunn et al., 2001). Exposure to $\mathrm{Al}$ in the present research, have examined all critical windows of immune development pre- and post natal till near adult status (Holsapple et al, 2005). The high Aldose exposure $(200 \mathrm{mg} / \mathrm{kg})$ was associated with increased Interferon- $\gamma$ production (T-helper type -1 associated activity), while $\mathrm{T}$ helper type 2 activities (Th2) that manifested in decreased IgE were contrasting what was reported in adult rodents (Hoe et al, 1997) and female rodent offspring exposed to lead throughout full gestation (Chen et al, 1999) as well as effects produced by aluminium vaccine adjuvants (HogenEsch, 2002).

Tumour necrosis factor- $\alpha(\mathrm{TNF}-\alpha)$ was found to be significantly increased with the highest dose group when compared to controls. This was in harmony with Hogen Esch (2002) and Exely et al, (2010) who observed that increment was associated with $\mathrm{Al}$ as a vaccine adjuvant. Additional experimental research concluded the same finding in chicks injected intraperitoneally with aluminium chloride (Liu et al, 2007). On the contrary, Zhu and associates (2012) observed reduction in TNF- $\alpha$ in aluminium chloride treated juvenile male ( 5 weeks old) rats in comparable dose regimens as designed for the present work. The observed different effects of $\mathrm{Al}$ on cellular and humoral immunity may be attributed to different Al compounds administered along with variable routes of exposure (Zhu et al., 2012).

$\mathrm{Al}$ included as an adjuvant in vaccination was concluded to be a potent and specific stimulator of Th2 immunity and presumably could not activate cytotoxic $\mathrm{T}$ cells (Hogen Esch, 2002) but recent evidence suggests that strong adjuvant effect or high Al dosage 
can overcome genetic resistance to autoimmunity mediated by excessive Th1 immune stimulation (Rose, 2010; Tomljenovic and Shaw, 2011). Elevated levels of TNF- $\alpha$ and Interferon- $\gamma$ have been reported to be associated with a variety of autoimmune diseases in human e.g. insulin dependent diabetes mellitus (Classen, 1996), systemic lupus erythrematosus (Aringer and Smolen, 2004), and multiple sclerosis (Girard, 2005). Moreover, the present immunological findings were in partial contrast to what previously concluded by Khalaf and associates (2008), who studied the immunotoxic behaviour of high doses of Al chloride $(345 \mathrm{mg} / \mathrm{kg})$ on rats' offspring. They received that dose regimen on the $6^{\text {th }}$ and $15^{\text {th }}$ day of gestation to the end of weaning. That Al exposure caused significant suppression of both cell mediated and humoral responses in comparison to control group.

In conclusion, the results of the present study indicated that exposure of aluminium ammonium sulphate as a member of food additives can induce immunotoxicologic effects in developing female offspring of rats. This was mainly in the form of cell mediated immune stimulation (Th1)as evidenced by elevated IFN- $\delta$ and TNF- $\alpha$ cytokines especially with maximum Al dosage administered. Additional developmental immunotoxicity studies are required to examine other critical windows of immune development either with early or late gestational exposure or after birth till weaning. Gender based difference in susceptibility to such immunotoxic behaviour of $\mathrm{Al}$ need to be further investigated as well.

\section{Acknowledgment}

This publication was made possible by a grant from the Faculty of Medicine's Grants Office, Assiut University. The authors wish to thank Prof. Dr. Ahmed Makhlouf and Dr. Omar Shaaban for their kind help in obtaining this fund on a transparent and a competitive basis.

\section{References}

Aguilar F, Autrup H., Barlow S, et al., (2007): Safety of Aluminium from dietary intake Scientific Opinion of the Panel on Food Additives, Flavorings, Processing Aids and Food Contact Materials (AFC).

Alfrey AC (1986 a): Aluminium metabolism. Kidney Int Suppl, 18, S8-11.

Alfrey AC (1986 b): Dialysis encephalopathy. Kidney Int Suppl, 18, S53-57.

Alleva E, Rankin J, and Santucci D (1998): Neurobehavioral alteration in rodents following developmental exposure to Aluminium. Toxicol Ind Health, 14 (1-2), 209-221.

Aringer $M$ and Smolen JS (2004): Tumor necrosis factor and other proinflammatory cytokines in systemic lupus erythematosus: a rationale for therapeutic intervention. Lupus, 13(5), 344347.

Batista-Duharte A, Lindblad EB, and Oviedo-Orta E (2011): Progress in understanding adjuvant immunotoxicity mechanisms. Toxicol Lett, 203(2), 97-105.

Bunn TL, Parsons PJ, Kao E, et al., (2001): Exposure to lead during critical windows of embryonic development: differential immunotoxic outcome based on stage of exposure and gender. Toxicol Sci, 64(1), 57-66.

Chen S, Golemboski KA, Sanders FS, et al., (1999): Persistent effect of in utero meso-2, 3dimercaptosuccinic acid (DMSA) on immune function and lead-induced immunotoxicity. Toxicology, 132(1), 67-79.

Chih-Hung G, Yi-Fa L, and Guoo-Shyng WH (2005): The influence of Aluminium exposure on male reproduction and offspring in mice. Environmental Toxicology and Pharmacology, 20, 135-141.

Classen JB (1996): Childhood immunization and diabetes mellitus. N Z Med J, 109(1022), 195.

Dietert RR, and Piepenbrink MS (2006): Perinatal immunotoxicity: why adult exposure assessment fails to predict risk. Environ Health Perspect, 114(4), 477-483.

Domingo JL (1995): Reproductive and developmental toxicity of Aluminium: a review. Neurotoxicol Teratol, 17(4), 515-521.

Exley C (2001): Aluminium and Alzheimer's disease. $J$ Alzheimers Dis, 3(6), 551-552.

Exley C (2005): The Aluminium-amyloid cascade hypothesis and Alzheimer's disease. Subcell Biochem, 38, 225-234.

Exley C, Siesjo P, and Eriksson H (2010): The immunobiology of Aluminium adjuvants: how do they really work? Trends Immunol, 31(3), 103-109.

Farina M, Lara FS, Brandao R, et al., (2002): Effects of Aluminium sulphate on erythropoiesis in rats. Toxicol Lett, 132(2), 131-139.

Farina M, Rotta LN, Soares FAA, et al., (2005): Hematological changes in rats chronically exposed to oral Aluminium. Toxicology 209 29-37

Fulton B and Jeffery EH (1994): Heme oxygenase induction. A possible factor in Aluminiumassociated anemia. Biol Trace Elem Res, 40(1), 9-19.

Girard M (2005): Autoimmune hazards of hepatitis B vaccine. Autoimmun Rev, 4(2), 96-100.

Glynn AW, Thuvander A., Sundstrom B, et al., (1999): Does Aluminium stimulate the immune system in male rats after oral exposure? Food Addit Contam, 16(3), 129-135.

Gomez M, Domingo JL, and Llobet JM (1991): Developmental toxicity evaluation of oral Aluminium in rats: influence of citrate. Neurotoxicol Teratol, 13(3), 323-328.

Gomez M, Esparza JL, Domingo JL, et al., (1999): Chelation therapy in Aluminium-loaded rats: influence of age. Toxicology, 137(3), 161168.

Gupta SK, Waters DH, and Gwilt PR (1986): Absorption and disposition of Aluminium in the rat. J Pharm Sci, 75(6), 586-589. 
Heo Y, Lee WT, and Lawrence DA (1997): In Vivo the Environmental Pollutants Lead and Mercury Induce Oligoclonal T Cell Responses Skewed toward Type-2 Reactivities. Cellular immunology, 179(2), 185-195.

Hogen Esch H (2002). Mechanisms of stimulation of the immune response by Aluminium adjuvants. Vaccine, 20 Suppl 3, S34-39

Holladay SD, and Smialowicz RJ (2000): Development of the murine and human immune system: differential effects of immunotoxicants depend on time of exposure. Environ Health Perspect, 108 Suppl 3, 463-473.

Holsapple MP, Burns-Naas LA, Hastings KL, et al., (2005): A proposed testing framework for developmental immunotoxicology (DIT). ToxicolSci, 83(1), 18-24.

Institute of Laboratory Animal Resources (US) (1996): Guide for the Care and Used of Laboratory Animals. National Academies Press.

Jaffe EK, Ali S, Mitchell LW, et al., (1995): Characterization of the role of the stimulatory magnesium of Escherichia coli porphobilinogen synthase. Biochemistry, 34(1), 244-251.

Johuanneau P, Lacour B, Raisbeck G, et al., (1994): Intestinal Aluminium absorption in rats using Aluminium-26. Life Chemistry Reports 11: 152-158.

Jordan MB, Mills DM, and Kappler J, et al., (2004): Promotion of B cell immune responses via an alum-induced myeloid cell population. Science, 304(5678), 1808-1810.

Khalaf AA, Morgan AM, Mekawy MM, Ali MF (2008): Immunotoxicity Following Pre-and Post-natal Aluminium Exposure in Rats. Toxicological Research, 24.

Liu FT, Li YF, and Gu QY (2007): The effects of Aluminium intoxication on the immune function of white and red blood cell in chicks.Chin.Anim.Husb.Vet.Med.34, 70-72.

Llobet JM, Colomina MT, Sirvent JJ, et al., (1995): Reproductive toxicology of Aluminium in male mice. Fundam Appl Toxicol, 25(1), 4551.

Luebke RW, Chen DH, Dietert R, et al., (2006): The comparative immunotoxicity of five selected compounds following developmental or adult exposure. J Toxicol Environ Health B Crit Rev, 9(1), 1-26.

Nasiadek M, Chmielnicka J, and Subdys J (2001): Analysis of urinary phorphyrins in rats exposed to Aluminium and iron. Ecotoxicol. Environ. Saf. 48 (1), 11-17.

Oberholzer A, Oberholzer C, and Moldawer LL (2000): Cytokine signaling--regulation of the immune response in normal and critically ill states. Crit Care Med, 28(4 Suppl), N3-12.

Pabello NG and Lawrence DA (2006): Neuroimmunotoxicology: Modulation of neuroimmune networks by toxicants. Clinical Neuroscience Research, 6, 69-85.
Parkinson TS, and Ward MK, and Kerr DNS (1981): Dialysis encephalopathy, bone disease and anemia: the Aluminium intoxication syndrome during regular haemodialysis. J. Clin. Pathol. 34, 1285-1294.

Paternain JL, Domingo JL, Llobet JM, et al., (1988): Embryotoxic and teratogenic effects of Aluminium nitrate in rats upon oral administration. Teratology, 38(3), 253-257.

Patterson R, Vega L, Trouba K., et al., (2004): Arsenic-induced alterations in the contact hypersensitivity response in Balb/c mice. Toxicol Appl Pharmacol, 198(3), 434-443.

Rengel Z (2004): Aluminium cycling in the soil-plantanimal-human continuum. Biometals, 17(6), 669-689.

Roig JL, Fuentes S, Teresa Colomina M, et al., (2006): Aluminium, restraint stress and aging: behavioral effects in rats after 1 and 2 years of Aluminium exposure. Toxicology, 218(2-3), 112-124.

Romagnani S, Kapsenberg M, Radbruch A, et al., (1998): Th1 and Th2 cells. Res Immunol, 149, 871-873.

Rose NR (2010): Autoimmunity, infection and adjuvants. Lupus, 19(4), 354-358.

Selgrade MK (2007): Immunotoxicity: the risk is real. ToxicolSci, 100(2), 328-332.

Sikorski EE, McCay JA, White KL, et al., (1989): Immunotoxicity of the semiconductor gallium arsenide in female B6C3F1 mice. Fundam Appl Toxicol, 13(4), 843-858.

Tomljenovic L and Shaw CA (2011): Aluminium vaccine adjuvants: are they safe? Curr Med Chem, 18(17), 2630-2637.

Tzanno-Martins C, Azevedo LS, Orii N, et al., (1996): The role of experimental chronic renal failure and aluminium intoxication in cellular immune response. Nephrol Dial Transplant, 11(3), 474-480.

Vittori D, Nesse A, Pe'rez G, et al., (1999): Morphologic and functional alterations of erythroid cells induced by long-term ingestion of Aluminium. J. Inorg. Biochem.76,113-120.

Ward RJ, McCrohan CR, White KN (2006): Influence of aqueous Aluminium on the immune system of the freshwater crayfish Pacifasticus leniusculus. Aquat Toxicol, 77(2), 222-228.

Yokel RA and McNamara PJ (2001): Aluminium toxicokinetics: an updated minireview. Pharmacol Toxicol, 88(4), 159-167.

Zaman K, Zaman W, and Siddique H (1993): Hematological and enzymatic results of Aluminium intoxication in rats. Comp. Biochem. Physiol. 150C, 73-76.

Zhu Y, Li X, Chen C, et al., (2012): Effects of Aluminium trichloride on the trace elements and cytokines in the spleen of rats. Food Chem Toxicol, 50(8), 2911-2915.

Zhu YZ, Liu DW, Liu ZY, et al., (2013): Impact of Aluminium exposure on the immune system: a mini review Environ Toxicol Pharmacol, $35(1), 82-87$. 


\section{الملخص العربي \\ السمية المناعية التطورية للألومونيوم كأحديبية مكنات المواد المضافة إلى الأغذية :دراسة المبية}

\section{غادة علي عمران و ميخائيل نظمي عجبان 1 و صفاء ماهر جورج2}

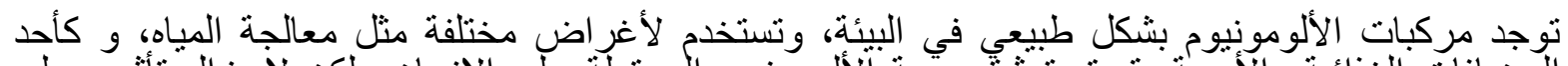

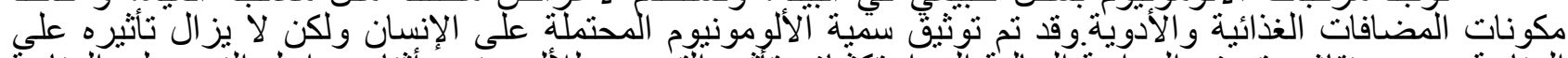

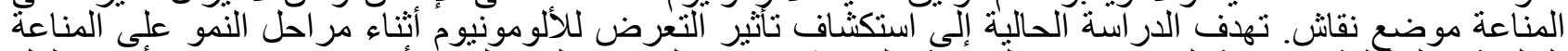

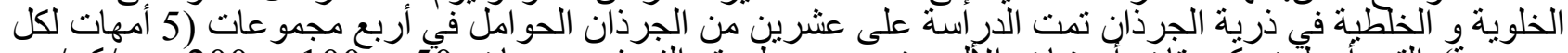

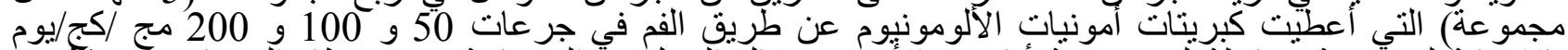

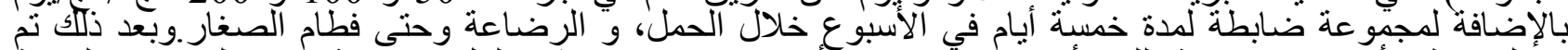

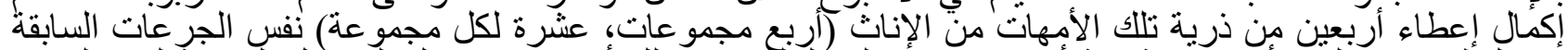

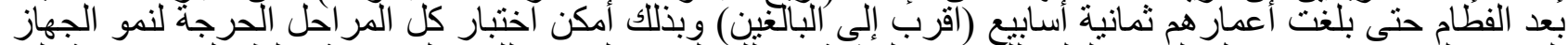

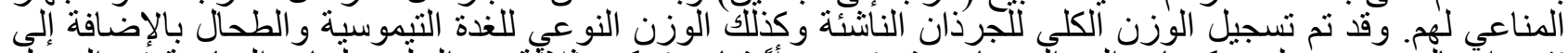

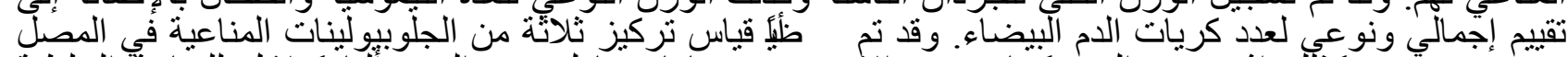

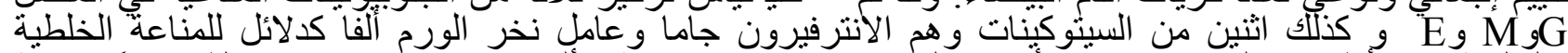

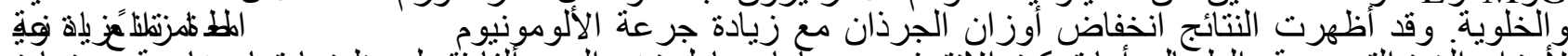

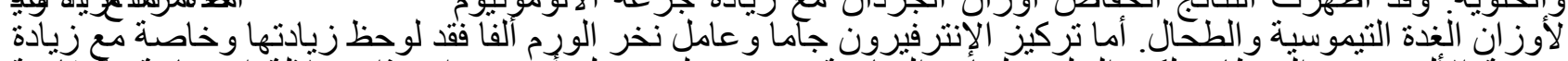

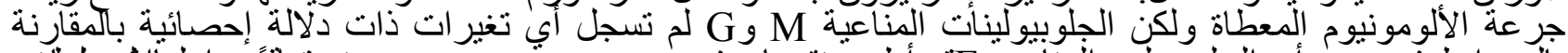

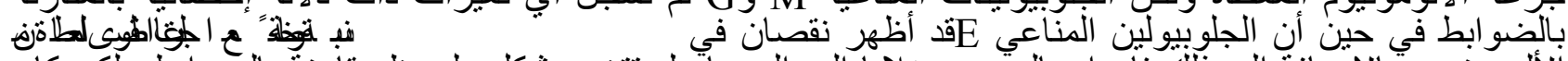

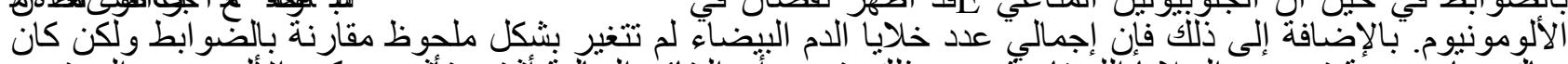

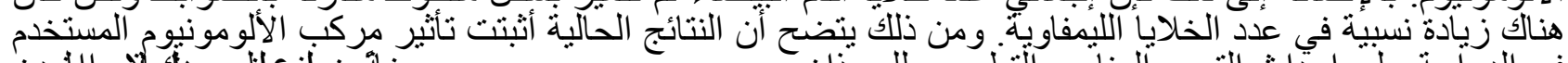

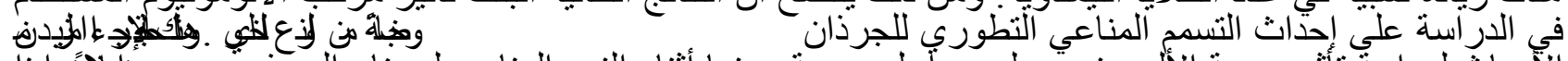

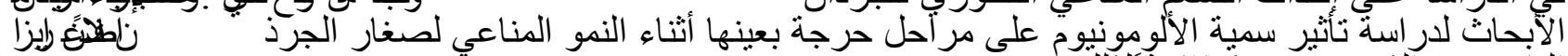

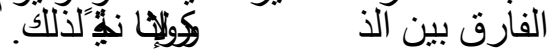

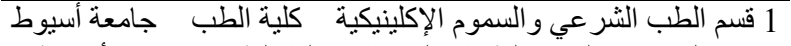

2 قسم الميكروبيولوجيا الطبية والمناعة كلية الطب جامعة أسيوط 